\title{
TATA HIJAU PADA RUANG JALAN MENUJU KENYAMANAN TERMAL IKLIM MIKRO Studi Kasus: Jalur Pedestrian, Penggal Jalan Slamet Riyadi Di Surakarta
}

\author{
Prasetyo Febriarto ${ }^{1}$ \\ ${ }^{1}$ Jurusan Sipil dan Perencanaan STIMK AMIKOM, Yogyakarta
}

\begin{abstract}
Abstrak
Tujuan dari penelitian ini adalah mendapatkan kondisi ideal dengan membuat nyaman jalur pedestrian berdasarkan kenyamanan termal iklim mikro. Metode yang digunakan adalah metode eksperimental melalui simulasi menggunakan software Envi-met 3.1 dengan pengukuran empirik. Metode dengan mensimulasi kondisi eksisting dan kondisi ideal. Hasilnya digunakan sebagai dasar arahan penataan jalur pedestrian ruang jalan Slamet Riyadi. Hasil dari penelitian ini menyatakan bahwa kenyamanan termal di jalur pedestrian ruang jalan Slamet Riyadi dalam kondisi tidak nyaman (panas) dan nyaman. Rekomendasi yang dihasilkan dari penelitian ini untuk menata jalur pedestrian berdasarkan kenyamanan termal iklim mikro berbasis tata hijau.
\end{abstract}

Kata kunci : iklim mikro, jalur pedestrian, kenyamanan termal, tata hijau

\begin{abstract}
The purpose of this study is to get ideal conditions to create a comfortable pedestrian ways based thermal comfort microclimate. The method used is an experimental method through simulation using Envi-met software 3.1 with empirical measurements. Method to simulate existing conditions and ideal conditions. The results are used as a basis for referral arrangement pedestrian ways of the Slamet Riyadi space road. The results of this study stated that the thermal comfort on the pedestrian ways of the Slamet Riyadi road space in uncomfortable conditions (heat) and comfortable. Recommendations resulting from this study to organize pedestrian ways based micro climate thermal comfort based design of greenery.
\end{abstract}

\section{Keywords : design of greenery, microclimate, pedestrian ways, thermal comfort}

\section{PENDAHULUAN}

\subsection{Latar Belakang Masalah}

Posisi Indonesia memiliki iklim tropis lembab karena terletak di sepanjang garis khatulistiwa.Efek tropis lembab berpengaruh terhadap aktivitas pembangunan perkotaanyang menyebabkan terjadinya thermal pollution dan membentuk pulau panas (heat island). Pulau panas dapat dikurangi dengan menanam pohon pada kawasan tersebut yang biasanya terdapat pada areal yang tidak bervegetasi. Suatu kota juga membutuhkan dan sangat perlu memiliki vegetasi yang mendukung dalam kehidupan kota.Vegetasi memiliki multifungsi yaitu berfungsi sebagai estetika, sebagai peneduh dan sebagai penyaring kebisingan serta fungsi visual.Seperti halnya di ruang Jalan Slamet Riyadi Kota Surakarta dengan akitivitas perkotaan yang padat menyebabkan terjadinya thermal pollution. Ruang jalanyang memunculkan berbagai fungsimeliputi perdagangan, jasa, pariwisata dan pemerintahan dan ruang publikdimana semakin padat dengan berbagai aktivitas. Minimya keteduhan dan tingginya suhu siang hari juga menyebabkan ketidaknyamanan bagi penggunajalan, terutama para pejalan kaki jalur pedestrian yaitu kenyamanan termal. Permasalahannya yaitu kondisi kenyamanan termal yang berhubungan dengan kondisi tata hijau dan belum tercapainya kondisi kenyamanan termal pada koridor jalur pedestrian. Pertanyaan penelitian sebagai berikut:

1. Bagaimana kondisi kenyamanan termal di jalur pedestrian koridor Jalan Slamet Riyadi?

2. Bagaimana optimalisasi tata hijau dalam kebutuhan pengguna yang dapat meningkatkan kenyamanan termal di jalur pedestrian koridor Jalan Slamet Riyadi?

3. Pelajaran dan rekomendasi perancangan tata hijau di jalur pedestrian?

Tujuan penelitiannya adalah menemukan optimalisasi/perbaikan kondisi ideal berbasis tata hijau di jalur pedestrian koridor Jalan Slamet Riyadi berdasarkan kondisi kenyamanan termal iklim mikro.

\section{ISI PENELITIAN}

\subsection{Metode Penelitian}

2.1.1. Lingkup Penelitian dan Batasan Penelitian Lingkup penelitian merupakan batasan topik yang akan dikaji atau diteliti, meliputi:

1. Mengkaji kondisi lokasi obyek penelitian dengan batasan termal kota/kawasan untuk menentukan faktor-faktor pengaruh secara makro yang akan ditujukan ke lokus penelitan.

2. Analisis terhadap kenyamanan termal koridor jalan pada jalur pedestrian dengan data 
perkembangan yang ada sebagai bahan dasar untuk analisis kenyamanan termal.

\subsubsection{Lokasi Penelitian}

Lokasi penelitian berada di Kota Surakarta, dengan lokasi khusus yaitu penggal Jalan Slamet Riyadi dengan lokasi fokus di jalur pedestrian, lokasi tersebut dipilih dalam penelitian karena merupakan lingkup mikro dengan pendekatan kenyamanan termal.

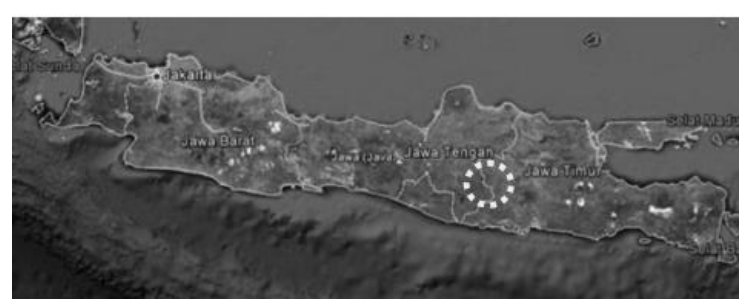

Gambar 1. Peta Pulau Jawa

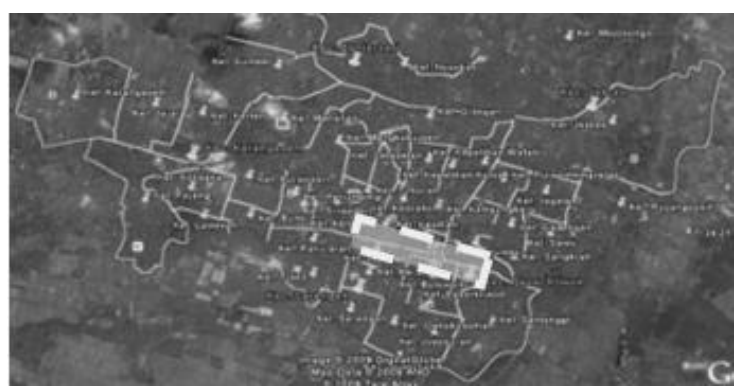

Gambar 2. Peta Surakarta

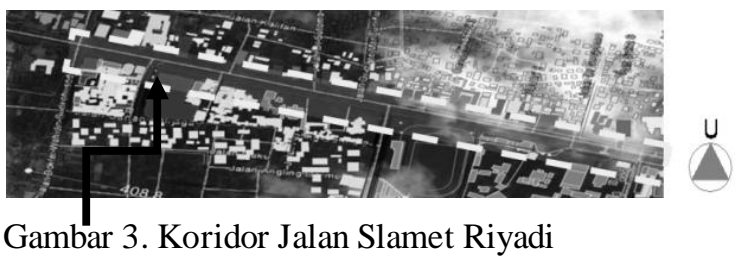

\subsubsection{Metode Studi}

Fokus penelitian ini adalah pada kualitas termal yang didapatkan pada jalur pedestrian penggal Jalan Brig.Jend Slamet Riyadi. Untuk mengetahui kualitas nyaman termal yang baik di kawasan ini, maka metoda yang digunakan dalam penelitian ini adalah dengan:

Metoda eksperimental melalui simulasi dengan pengukuran empirik, untuk memperlihatkan kualitas termal dan hasil analisis termal yang dilakukan dengan menggunakan data-data yang diukur dilokasi.

Ada tiga proses simulasi, yaitu:

1. Pengukuran empirik, untuk memperlihatkan kondisi termal dan hasil analisis termal yang dilakukan dengan menggunakan data-data yang diukur dilokasi dengan menggunakan alat ukur tertentu.

2. Simulasi dengan menggunakan software Envimet system untuk mengetahui pengaruh tatanan ruang eksisting terhadap kondisi termal.

3. Simulasi optimalisasi (dengan menggunakan tambahan aplikasi di software Envi-met system) yaitu Leonardo yang berfungsi untuk memberikan visualisasi menuju kondisi ideal.

\subsubsection{Tahapan penelitian:}

1. Tahapan persiapan penelitian

a. Survey awal, dengan mengenali permasalahan yang ada di lapangan.

b. Pengumpulan data, berupa peta dasar dan data tentang kondisi iklim kota Surakarta.

c. Identifikasi data awal, mengenali data dan menyusun data untuk keperluan kesimpulan awal dan penentuan variabel yang dijadikan pegangan untuk tahap survei kedua untuk melihat temuan di lokasi penelitian.

2. Tahapan penelitian

Dokumentasi dilakukan untuk mengumpulkan data sekunder yang digunakan untuk melengkapi data primer (observasi/pengukuran) yang telah diperoleh.

3. Tahapan analisis

a. Tahap identifikasi lapangan dan pengumpulan data.

b. Tahap simulasi permodelan simulasi eksisting dan kondisi ideal dengan menggunakan software Envi-Met.

c. Menganalisis hasil simulasi eksisiting dan kondisi ideal yang telah didapat yang kemudian digunakan sebagai pertimbangan dalam perbaikan kondisi ideal kenyamanan termal berbasis tata hijau penataan ruang publik.

\subsection{Hasil Penelitian dan Pembahasan}

Pengukuran dilakukan pada ketinggian 1,20 meter dengan asumsi bahwa pada ketinggian ini pengguna akan sangat merasakan kondisi kenyamanan termal. Pengukuran dilakukan pada 3 waktu yang berbeda yaitu pagi (pukul 07.00 WIB dan 10.00 WIB), siang (pukul 13.00 WIB) dan sore (pukul 16.00 WIB).

\section{a) Kenyamanan Termal pada Penggal 1 Jalur} Pedestrian

Titik pengukuran di lokasi amatan dilakukan di jalur pedestrian depan Solo Grand Mall.

Berikut hasil pengukuran kondisi eksisting penggal 1:

Tabel.1. Hasil pengukuran kondisi eksisting

\begin{tabular}{|c|c|c|c|}
\hline Nilai & Temp & Kelembaban & Temp efektif \\
\hline 07.00 & $27,5^{\circ} \mathrm{C}$ & $83 \%$ & $26^{\circ} \mathrm{CTE}$ \\
\hline kategori & \multicolumn{3}{|l|}{ nyaman } \\
\hline Nilai & Temp & Kelembaban & Temp efektif \\
\hline 10.00 & $32,6^{\circ} \mathrm{C}$ & $60 \%$ & $28,5^{\circ} \mathrm{CTE}$ \\
\hline kategori & \multicolumn{3}{|c|}{ Tidak nyaman } \\
\hline Nilai & Temp & Kelembaban & Temp efektif \\
\hline 13.00 & $34,5^{\circ} \mathrm{C}$ & $51 \%$ & $29^{\circ} \mathrm{C} \mathrm{TE}$ \\
\hline kategori & \multicolumn{3}{|c|}{ Tidak nyaman } \\
\hline
\end{tabular}




\begin{tabular}{|l|c|c|c|}
\hline Nilai & Temp & Kelembaban & Temp efektif \\
\hline $\mathbf{1 6 . 0 0}$ & $\mathbf{3 0 ^ { \circ } \mathbf { C }}$ & $\mathbf{7 3 \%}$ & $\mathbf{2 7 , 5} \mathbf{5}^{\circ} \mathbf{C} \mathbf{C E}$ \\
\hline kategori & \multicolumn{2}{|l|}{ Tidak nyaman } & \\
\end{tabular}

Kemudian hasil pengukuran menjadi input sebagai simulasi termal pada Envi-met 3.1 BETA 5 pada Selasa, 20 November 2012. Menggunakan luas grid, penggal 1 (x-grids: 224, y-grids: 34, z-grids: 25 ), dengan dimensi masing-masing sel grid $\mathrm{x}=2, \mathrm{y}=2$, $\mathrm{z}=2$ meter.

Berikut hasil simulasi envimet kondisi eksisting penggal 1:

Tabel.2. Hasil simulasi kondisi eksisting

Pukul 07.00 WIB

\begin{tabular}{|c|c|c|c|}
\hline Nilai & Temp & Kelembaban & Temp efektif \\
\hline terendah & $22,67^{\circ} \mathrm{C}$ & $93,96 \%$ & $22,15^{\circ} \mathrm{CTE}$ \\
\hline tertinggi & $23,60^{\circ} \mathrm{C}$ & $88,36 \%$ & $22,80^{\circ} \mathrm{CTE}$ \\
\hline kategori & \multicolumn{3}{|c|}{$\begin{array}{l}\text { Fidaknyaman/nyaman / sebagian area nyaman } \\
\text { sebagian area tidaknyaman }\end{array}$} \\
\hline \multicolumn{4}{|c|}{ Pukul 10.00 WIB } \\
\hline Nilai & Temp & Kelembaban & Temp efektif \\
\hline terendah & $27,64^{\circ} \mathrm{C}$ & $80,24 \%$ & $26,10^{\circ} \mathrm{CTE}$ \\
\hline tertinggi & $28,48^{\circ} \mathrm{C}$ & $80,24 \%$ & $26,70^{\circ} \mathrm{CTE}$ \\
\hline kategori & \multicolumn{3}{|c|}{$\begin{array}{l}\text { Tidak nyaman/nyaman/sebagian area nyaman } \\
\text { sebagian area tidaknyaman }\end{array}$} \\
\hline \multicolumn{4}{|c|}{ Pukul 13.00 WIB } \\
\hline Nilai & Temp & Kelembaban & Temp efektif \\
\hline terendah & $28,66^{\circ} \mathrm{C}$ & $74,95 \%$ & $26,40^{\circ} \mathrm{CTE}$ \\
\hline tertinggi & $29,64^{\circ} \mathrm{C}$ & $83,62 \%$ & $28,00^{\circ} \mathrm{CTE}$ \\
\hline kategori & \multicolumn{3}{|c|}{$\begin{array}{l}\text { Tidak nyaman/nyaman/sebagian area nyaman } \\
\text { sebagian area tidaknyaman }\end{array}$} \\
\hline \multicolumn{4}{|c|}{ Pułul 16.00 WIB } \\
\hline Nilai & Temp & Kelembaban & Temp efektif \\
\hline terendah & $23,65^{\circ} \mathrm{C}$ & $96,53 \%$ & $23,30^{\circ} \mathrm{CTE}$ \\
\hline tertinggi & $25,46^{\circ} \mathrm{C}$ & $88,42 \%$ & $24,50^{\circ} \mathrm{CTE}$ \\
\hline kategori & \multicolumn{3}{|c|}{$\begin{array}{l}\text { Fidaknyaman/nyaman / sebagian area nyaman } \\
\text { sebagian area tidaknyaman }\end{array}$} \\
\hline
\end{tabular}

b) Kenyamanan Termal pada Penggal 2 Jalur Pedestrian

Pengukuran dilakukan di depan rest area dan lahan kosong milik Bank Mandiri.

Berikut hasil pengukuran kondisi eksisting penggal 2:

Tabel.3. Hasil pengukuran kondisi eksisting

\begin{tabular}{|c|c|c|c|}
\hline Nilai & Temp & Kelembaban & Temp efektif \\
\hline 07.00 & $27,2^{\circ \mathrm{C}}$ & $80 \%$ & $25,7^{\circ} \mathrm{C} \mathrm{TE}$ \\
\hline kategori & nyaman & & \\
\hline Nilai & Temp & Kelembaban & Temp efektif \\
\hline 10.00 & $31,3^{\circ} \mathrm{C}$ & $63 \%$ & $27,5^{\circ} \mathrm{CIE}$ \\
\hline kategori & Tidak ny & nan & \\
\hline
\end{tabular}

\begin{tabular}{|c|c|c|c|}
\hline Nilai & Temp & Kelembaban & Temp efektif \\
\hline 13.00 & $31,8^{\circ} \mathrm{C}$ & $64 \%$ & $28,2^{\circ} \mathrm{CTE}$ \\
\hline kategori & \multicolumn{3}{|c|}{ Tidak nyaman } \\
\hline Nilai & Temp & Kelembaban & Temp efektif \\
\hline 16.00 & $30,8^{\circ} \mathrm{C}$ & $63 \%$ & $27,2^{\circ} \mathrm{CTE}$ \\
\hline kategori & \multicolumn{3}{|c|}{ Tidak nyaman } \\
\hline
\end{tabular}

Kemudian hasil pengukuran menjadi input sebagai simulasi termal pada Envi-met 3.1 BETA 5 pada Rabu, 21 November 2012.Menggunakan luas grid, penggal 2 (x-grids: 204, y-grids: 34, z-grids: 25), dengan dimensi masing-masing sel grid $x=2, y=2$, $\mathrm{z}=2$ meter.

Berikut hasil simulasi envimet kondisi eksisting penggal 2:

Tabel.4. Hasil simulasi kondisi eksisting

Pukul 07.00 WIB

\begin{tabular}{|l|l|l|l|}
\hline Nilai & Temp & Kelembaban & Temp efektif \\
\hline terendah & $22,80^{\circ} \mathrm{C}$ & $93,82 \%$ & $22,30^{\circ} \mathrm{CTE}$ \\
\hline tertinggi & $23,91^{\circ} \mathrm{C}$ & $92,64 \%$ & $23,40^{\circ} \mathrm{CTE}$ \\
\hline kategori & $\begin{array}{l}\text { Fidaknyaman/nyaman / sebagian area nyaman } \\
\text { sebagianarea tidaknyaman }\end{array}$ &
\end{tabular}

Pukul 10.00 WIB

\begin{tabular}{|l|l|l|l|}
\hline Nilai & Temp & Kelembaban & Temp efektif \\
\hline terendah & $25,91^{\circ} \mathrm{C}$ & $91,72 \%$ & $25,20^{\circ} \mathrm{CTE}$ \\
\hline tertinggi & $28,22^{\circ} \mathrm{C}$ & $86,34 \%$ & $26,80^{\circ} \mathrm{CTE}$ \\
\hline kategori & $\begin{array}{l}\text { Fidaknyaman/nyaman/sebagian area nyaman } \\
\text { sebagian area tidak nyaman }\end{array}$ &
\end{tabular}

Pukul 13.00 WIB

\begin{tabular}{|l|l|l|l|}
\hline Nilai & Temp & Kelembaban & Temp efektif \\
\hline terendah & $27,03^{\circ} \mathrm{C}$ & $92,28 \%$ & $26,35^{\circ} \mathrm{C} \mathrm{TE}$ \\
\hline tertinggi & $29,08^{\circ} \mathrm{C}$ & $82,08 \%$ & $27,40^{\circ} \mathrm{CTE}$ \\
\hline kategori & $\begin{array}{l}\text { Tidaknyaman/nyaman/sebagian area nyaman } \\
\text { sebagianareatidaknyaman }\end{array}$ & \multicolumn{2}{l}{} \\
\hline
\end{tabular}

Pukul 16.00 WIB

\begin{tabular}{|l|l|l|l|}
\hline Nilai & Temp & Kelembaban & Temp efektif \\
\hline terendah & $24,07^{\circ} \mathrm{C}$ & $91,45 \%$ & $23,55^{\circ} \mathrm{C} \mathrm{TE}$ \\
\hline tertinggi & $26,31^{\circ} \mathrm{C}$ & $91,45 \%$ & $25,70^{\circ} \mathrm{C} \mathrm{TE}$ \\
\hline kategori & $\begin{array}{l}\text { Fidaknyaman/nyaman / sebagian area nyaman } \\
\text { sebagianarea tidaknyaman }\end{array}$ &
\end{tabular}

c) Kenyamanan Termal pada Penggal 3 Jalur Pedestrian

Pengukuran dilakukan di depan plaza pintu gerbang masuk Taman Sriwedari.

Berikut hasil pengukuran kondisi eksisting penggal 3:

Tabel.5. Hasil pengukuran kondisi eksisting

\begin{tabular}{|c|c|c|c|}
\hline Nilai & Temp & Kelembaban & Temp efektif \\
\hline 07.00 & $27,5^{\circ} \mathrm{C}$ & $80 \%$ & $25,8^{\circ} \mathrm{CTE}$ \\
\hline kategori & nyaman & & \\
\hline
\end{tabular}




\begin{tabular}{|c|c|c|c|}
\hline Nilai & Temp & Kelembaban & Temp efektif \\
\hline 10.00 & $32,4^{\circ} \mathrm{C}$ & $62 \%$ & $28,3^{\circ} \mathrm{C}$ TE \\
\hline kategori & \multicolumn{3}{|c|}{ Tidak nyaman } \\
\hline Nilai & Temp & Kelembaban & Temp efektif \\
\hline 13.00 & $32,8^{\circ} \mathrm{C}$ & $56 \%$ & $28,1^{\circ} \mathrm{CTE}$ \\
\hline kategori & \multicolumn{3}{|c|}{ Tidak nyaman } \\
\hline Nilai & Temp & Kelembaban & Temp efektif \\
\hline 16.00 & $26,3^{\circ} \mathrm{C}$ & $90 \%$ & $25,5^{\circ} \mathrm{CTE}$ \\
\hline kategori & nyaman & & \\
\hline
\end{tabular}

Kemudian hasil amatan menjadi input sebagai simulasi termal pada Envi-met 3.1 BETA 5 pada Kamis, 22 November 2012. Menggunakan luas grid, penggal 3 (x-grids: 183, y-grids: 34, z-grids: 25 ), dengan dimensi masing-masing sel grid $\mathrm{x}=2, \mathrm{y}=2$, $\mathrm{z}=2$ meter.

Berikut hasil simulasi envimet kondisi eksisting penggal 3:

Pukul 07.00 WIB

Tabel.6. Hasil simulasi kondisi eksisting

\begin{tabular}{|l|l|l|l|}
\hline Nilai & Temp & Kelembaban & Temp efektif \\
\hline terendah & $23,03^{\circ} \mathrm{C}$ & $93,65 \%$ & $22,40^{\circ} \mathrm{CTE}$ \\
\hline tertinggi & $23,73^{\circ} \mathrm{C}$ & $92,06 \%$ & $23,20^{\circ} \mathrm{CTE}$ \\
\hline kategori & $\begin{array}{l}\text { Fidaknyaman/nyaman / sebagian areanyaman } \\
\text { sebagianarea tidaknyaman }\end{array}$ \\
& \multicolumn{3}{l}{}
\end{tabular}

Pukul 10.00 WIB

\begin{tabular}{|l|l|l|l|}
\hline Nilai & Temp & Kelembaban & Temp efektif \\
\hline terendah & $26,38^{\circ} \mathrm{C}$ & $88,97 \%$ & $25,30^{\circ} \mathrm{CTE}$ \\
\hline tertinggi & $28,02^{\circ} \mathrm{C}$ & $93,24 \%$ & $27,30^{\circ} \mathrm{CTE}$ \\
\hline kategori & $\begin{array}{l}\text { Fidaknyaman/nyaman/sebagian area nyaman } \\
\text { sebagian area tidak nyaman }\end{array}$ &
\end{tabular}

Pukul 13.00 WIB

\begin{tabular}{|l|l|l|l|}
\hline Nilai & Temp & Kelembaban & Temp efektif \\
\hline terendah & $27,33^{\circ} \mathrm{C}$ & $84,57 \%$ & $26,00^{\circ} \mathrm{C}$ TE \\
\hline tertinggi & $28,81^{\circ} \mathrm{C}$ & $93,51 \%$ & $28,15^{\circ} \mathrm{C}$ TE \\
\hline kategori & $\begin{array}{l}\text { Fidaknyaman/nyaman/sebagian area nyaman } \\
\text { sebagian area tidak nyaman }\end{array}$ &
\end{tabular}

Pukul 16.00 WIB

\begin{tabular}{|l|l|l|l|}
\hline Nilai & Temp & Kelembaban & Temp efektif \\
\hline terendah & $23,44^{\circ} \mathrm{C}$ & $99,55 \%$ & $23,40^{\circ} \mathrm{C} \mathrm{TE}$ \\
\hline tertinggi & $25,60^{\circ} \mathrm{C}$ & $87,77 \%$ & $24,70^{\circ} \mathrm{C} \mathrm{TE}$ \\
\hline kategori & $\begin{array}{l}\text { Fidaknyaman/nyaman / sebagian area nyaman } \\
\text { sebagianarea tidaknyaman }\end{array}$ \\
& \multicolumn{2}{l}{} &
\end{tabular}

\subsubsection{Temuan pada Jalur Pedestrian Ruang Jalan Slamet Riyadi}

Setelah proses analisis tata hijau ruang jalan jalur pedestrian melalui observasi, pengolahan data, dan dengan software Envi-met yang telah dilakukan, maka muncul temuan pada penelitian jalur pedestrian, yaitu:
1. Arah datang sinar matahari yang jatuh mengenai kanopi vegetasi dan permukaan site yang mempengaruhi disekitarnya pada jam tertentu.

2. Tajuk vegetasi yang rindang dan dengan jarak yang rapat dapat menghalangi dan merubah alur angin.

3. Tajuk vegetasi yang rindang dan dengan jarak yang rapat dapat meningkatkan kelembaban udara.

4. Tajuk vegetasi yang rindang mampu menaungi permukaan site yang tertutup hard material (perkerasan dan dinding) berkontribusi dalam meningkatkan termal.

5. Permukaan site yang tertutup material perkerasa yang tidak ternaungi atau sedikit ternaungi tajuk vegetasi yang rindang cenderung memiliki temperatur tinggi.

Mendapatkan suatu kondisi ideal yang lebih baik dari eksisting perlu dilakukan simulasi optimalisasi dengan mengambil waktu pagi (pukul 07.00 WIB) dan siang (pukul 13.00 WIB) untuk melihat kondisi terdingin dan terpanas.

2.2.2. Simul asi Optimalisasi Kenyamanan Termal Jal ur Pedestrian ruang jalan Slamet Riyadi

Simulasi dilakukan dengan penerapan elemen modifikasi yang dapat diaplikasikan dalam Envi$m e t$, elemen tersebut adalah vegetasi dengan cara:

a) Mengubah vegetasi menjadi keteduhan massa pohon/kepadatan kanopi, menambahkan vegetasi yang dipakai dalam simulasi ini antara lain jenis $\mathrm{Tb}$ (pohon rindang) ketinggian 15 meter, DO (pohon rindang) ketinggian 20 meter, ds (pohon rindang) ketinggian 10 meter dan lg, $\mathrm{xx}$ atau rumput. Mengubah hijau dengan cara : tempat jalur tanaman di jalur pedestrian perlu vegetasi berupa $\mathrm{Tb}$ (pohon bertajuk rindang), DO (pohon bertajuk rindang). Ruang terbuka yang tanpa teduhan perlu $\mathrm{Tb}$ (pohon bertajuk rindang). Perlu jarak antar tanaman sekitar 8 meter agar dapat memberikan visual yang nyaman.

b) Tujuan mengubahnya: Menyebabkan menurunkan suhu lingkungan pada permukaan site (jalur pedestrian) yang bersifat peneduh dengan keteduhan massa pohon.

Dengan simulasi optimasi disimpulkan bahwa intervensi terhadap vegetasi dapat menciptakan kondisi kenyamanan termal yang lebih baik dari sebelumnya (eksisting). Berikut hasil simulasi optimalisasi kondisi ideal tata hijau:

Simul asi Optimalisasi Tata Hijau Penggal 1 Jal ur Pedestrian Pukul 07.00 dan 13.00 WIB

Tabel.7. Hasil simulasi kondisi ideal Pukul 07.00 WIB

\begin{tabular}{|c|c|c|c|}
\hline Nilai & Temp & Kelembaban & Temp efektif \\
\hline terendah & $22,16^{\circ} \mathrm{C}$ & $99,24 \%$ & $22,05^{\circ} \mathrm{CTE}$ \\
\hline tertinggi & $23,58^{\circ} \mathrm{C}$ & $89,41 \%$ & $22,90^{\circ} \mathrm{CTE}$ \\
\hline kategori & \multicolumn{3}{|c|}{$\begin{array}{l}\text { Fidaknyaman/nyaman / sebagian area nyaman } \\
\text { sebagian area tidaknyaman }\end{array}$} \\
\hline
\end{tabular}


Pukul 13.00 WIB

\begin{tabular}{|c|c|c|c|}
\hline Nilai & Temp & Kelembaban & Temp efektif \\
\hline terendah & $26,10^{\circ} \mathrm{C}$ & $85,33 \%$ & $25,00^{\circ} \mathrm{CTE}$ \\
\hline tertinggi & $29,83^{\circ} \mathrm{C}$ & $66,48 \%$ & $26,50^{\circ} \mathrm{CTE}$ \\
\hline kategori & \multicolumn{3}{|c|}{$\begin{array}{l}\text { Fidaknyaman/nyaman/sebagian area nyaman } \\
\text { sebagian area tidak nyaman }\end{array}$} \\
\hline
\end{tabular}

\section{Simulasi Optimalisasi Tata Hijau Penggal 2 Jalur Pedestrian Pukul 07.00 dan 13.00 WIB}

Tabel.8. Hasil simulasi kondisi ideal Pukul 07.00 WIB

\begin{tabular}{|l|l|l|l|}
\hline Nilai & Temp & Kelembaban & Temp efektif \\
\hline terendah & $23,12^{\circ} \mathrm{C}$ & $92,12 \%$ & $22,60^{\circ} \mathrm{C}$ TE \\
\hline tertinggi & $24,20^{\circ} \mathrm{C}$ & $92,12 \%$ & $23,70^{\circ} \mathrm{C} \mathrm{TE}$ \\
\hline kategori & $\begin{array}{l}\text { Fidaknyaman/nyaman / sebagian areanyaman } \\
\text { sebagianarea tidaknyaman }\end{array}$ \\
& \multicolumn{4}{l}{$l$}
\end{tabular}

Pukul 13.00 WIB

\begin{tabular}{|l|l|l|l|}
\hline Nilai & Temp & Kelembaban & Temp efektif \\
\hline terendah & $25,69^{\circ} \mathrm{C}$ & $89,44 \%$ & $24,85^{\circ} \mathrm{C} \mathrm{TE}$ \\
\hline tertinggi & $27,96^{\circ} \mathrm{C}$ & $76,24 \%$ & $25,90^{\circ} \mathrm{C} \mathrm{TE}$ \\
\hline kategori & $\begin{array}{l}\text { Tidaknyaman/nyaman / sebagian area nyaman } \\
\text { sebagianarea tidaknyaman }\end{array}$ & \multicolumn{2}{l}{} \\
& &
\end{tabular}

Simulasi Optimalisasi Tata Hijau Penggal 3 Jalur Pedestrian Pukul 07.00 dan 13.00 WIB

Tabe1.9. Hasil simulasi kondisi ideal

Pukul 07.00 WIB

\begin{tabular}{|l|l|l|l|}
\hline Nilai & Temp & Kelembaban & Temp efektif \\
\hline terendah & $23,34^{\circ} \mathrm{C}$ & $94,68 \%$ & $22,80^{\circ} \mathrm{CTE}$ \\
\hline tertinggi & $24,46^{\circ} \mathrm{C}$ & $89,29 \%$ & $23,80^{\circ} \mathrm{C} \mathrm{TE}$ \\
\hline kategori & $\begin{array}{l}\text { Fidaknyaman/nyaman / sebagian area nyaman } \\
\text { sebagianarea tidaknyaman }\end{array}$ \\
& \multicolumn{3}{l}{}
\end{tabular}

Pukul 13.00 WIB

\begin{tabular}{|l|l|l|l|}
\hline Nilai & Temp & Kelembaban & Temp efektif \\
\hline terendah & $25,87^{\circ} \mathrm{C}$ & $82,90 \%$ & $24,50^{\circ} \mathrm{C} \mathrm{TE}$ \\
\hline tertinggi & $28,40^{\circ} \mathrm{C}$ & $70,61 \%$ & $25,90^{\circ} \mathrm{C} \mathrm{TE}$ \\
\hline kategori & $\begin{array}{l}\text { Fidaknyaman/nyaman / sebagian area nyaman } \\
\text { sebagianarea tidaknyaman }\end{array}$ \\
& \multicolumn{3}{l}{}
\end{tabular}

\section{Temuan - Temuan}

1. Ukuran vegetasi pohon tinggi dan bentuk serta fungsi vegetasi peneduh (bulat, rindang dan lebat).

2. Jarak antar tanaman (renggang, sangat renggang) dan posisi vegetasi yang teratur (sebaris) agar kesan kemenarikan visual bangunan tetap ada.

3. Tinggi pohon dengan tinggi 15 sampai 20 meter.

4. Tajuk vegetasi yang rindang dan dengan jarak yang tidak rapattidak menghalangi dan merubah alur angin.

5. Tajuk vegetasi yang rindang dan dengan jarak yang tidak rapat dapat mengurangi kelembaban udara.
6. Tajuk vegetasi yang rindang mampu menaungi permukaan site yang tertutup hard material (perkerasan dan dinding).

\section{KESIMPULAN}

Kondisi kenyamanan termal eksisting masih tergolong panas (tidak nyaman) terutama pada siang hari. Hal ini disebabkan oleh beberapa faktor yaitu:

1. Arah datang sinar matahari yang jatuh mengenai kanopi vegetasi dan permukaan site yang mempengaruhi disekitarnya pada jam tertentu.

2. Tajuk vegetasi yang rindang dan dengan jarak yang rapat dapat menghalangi dan merubah alur angin.

3. Tajuk vegetasi yang rindang dan dengan jarak yang rapat dapat meningkatkan kelembaban udara.

4. Tajuk vegetasi yang rindang mampu menaungi permukaan site yang tertutup hard material (perkerasan dan dinding) berkontribusi dalam meningkatkan termal.

5. Permukaan site yang tertutup material perkerasa yang tidak ternaungi atau sedikit ternaungi tajuk vegetasi yang rindang cenderung memiliki temperatur tinggi.

\section{a. Rekomendasi}

Modifikasi dilakukan di kawasan kepadatan bangunan tinggi, minim dan sedang denganpenambahan vegetasi bertajuk rindang sebagai peneduh dengan ketinggian sekitar 15 dan 20 meter.Penambahan tersebut dilakukan di area jalur tanaman jalur pedestrian berupa penanaman sebaris dengan jarak antar tanaman 8 dan 12 meter. Penambahan vegetasi bertajuk rindang juga dilakukan di area terbuka seperti lahan parkir, dan ruang terbuka di antara bangunan. Pola penataan di kedua area tersebut sebaiknya berupa grid kotak jamak dan tunggal dengan jarak antar tanaman sekitar 8 meter. Penambahan vegetasi juga diterapkan sebagai pengarah dan pembatas ruang dapat dilakukan di area terbuka hijau yang dalam keadaan tidak terurus dan gersang. Dilakukan juga di jalur koridor penghubung jalan utama dan di jalur pedestrian yang berbatasan dengan area bangunan dengan tetap mengedepankan kemenarikan visual bangunan dengan ketinggian 10-15 meter.

\section{b. Saran Penelitian Selanjutnya}

1. Modifikasi lebih detail tentang jenis tanaman dimulai dari bentuk tajuk, kerapatan tajuk, jarak antar tanaman akan berpengaruh pada kenyamanan termal sehingga diketahui jenis tanaman yang paling efektif berpengaruh positif terhadap iklim mikro kawasan.

2. Modifikasi penambahan green roof, vertical garden dapat dikaji lebih jauh terutama pada tatanan ruang dengan kepadatan bangunan yang tinggi. Diharapkan dapat diketahui lebih lanjut, hal-hal yang berdampak positif terhadap 
kenyamanan termal iklim mikro kawasan jalur pedestrian.

\section{DAFTAR PUSTAKA}

- Booth, Norma K. 1983. Basic Element of Landscape Architectural Design. New York : Elsevier Science Publishing Co.

- Fandeli, Chafid, Kaharuddin, Mukhlison. 2004. Perhutanan Kota.Yogyakarta : Fakultas Kehutanan Uni versitas Gadjah Mada.

- $\quad$ Frick, Heinz, FX. Bambang Suskiyatno. 2007. Dasar-Dasar Arsitektur Ekologis. Yogyakarta: Penerbit Kanisius, Bandung: Penerbit ITB.

- Lippsmeier, George. 1994. Bangunan Tropis. Jakarta : Penerbit Erlangga.

- Satwiko, Prasasto.2009. Fisika Bangunan. Yogyakarta : Penerbit ANDI Yogyakarta.

- Sugijanto. 1998. Bangunan di Indonesia dengan Iklim Tropis Lembab ditinjau dari Aspek Fisika Bangunan, Fakultas Teknologi Industri ITB. Jakarta: Dirjen Dikti Depdiknas.

Website:

Sumber : www.envi-met.com.pdf, diakses 10 Desember 2012, pukul 10.00 WIB

Sumber : https://www.google.co.id/Pengembangan Tata Hijau Terhadap Kenyamanan Pengguna Jalan di Kota Makasar.pdf, diakses 10 Februari 2013, pukul 16.00 WIB 